\title{
POSTNATAL DEVELOPMENT OF THE AFFERENT INNERVATION OF THE MAMMALIAN COCHLEA
}

\author{
Emylian A. Ivanov ${ }^{1}$ and Nikolai E. Lazarov ${ }^{2,3}$ \\ ${ }^{1}$ Department of Anatomy, Histology and Cytology, Medical University, Pleven, Bulgaria; ${ }^{2}$ Department \\ of Anatomy and Histology, Medical University, Sofia, Bulgaria; ${ }^{3}$ Institute of Neurobiology, Bulgarian \\ Academy of Sciences, Sofia, Bulgaria
}

The adult mammalian cochlea receives dual afferent innervation: the inner hair cells (IHCs) are innervated exclusively by type I spiral ganglion neurons (SGNS), whereas the outer hair cells (OHCS) are innervated by type II SGNs. We have characterized the reorganization and morphology of this dual afferent innervation pattern as it is established in the developing rat cochlea. Before the cochlear afferent innervation reaches a mature configuration, there is an initial mismatch, where both populations of SGNs innervate both types of sensory hair cells: during the first postnatal week in the rat cochlea, type I SGN innervation is eliminated from the OHC and type II SGN innervation is eliminated from the IHC. This reorganization occurs during the first two postnatal weeks just before the onset of hearing. Our data reveal distinct phases in the development of the afferent innervation of the organ of Corti: neurite refinement, with a formation of the outer spiral bundles innervating outer hair cells; neurite retraction and synaptic pruning to eliminate type I SGN innervation of OHCs, while retaining their supply to IHCs. Such a reorganization also makes the cochlea a model system for studying CNS synapse development, plasticity and elimination. The present article summarizes the recent progress in our understanding of the afferent innervation of the cochlea. Biomed Rev 2012; 23: 37-52.

Key words: calcium channels, hair cells, organ of Corti, rat, ribbon synapse, spiral ganglion neurons

\section{INTRODUCTION}

Mechanosensory hair cells of the inner ear convert sound waves or head motion into bioelectrical signals for propagation throughout the nervous system. Mechanotransduction begins at the hair bundle where gated ionic flux changes the hair cells membrane potential. This initial bioelectrical event is com- municated centrally through a chemical synapse between the hair cell and an associated afferent fiber of the eighth cranial nerve (1). The adult cochlea contains two types of auditory receptors, termed inner hair cells (IHCs) and outer hair cells (OHCs), which receive separate and highly distinctive patterns

Received 10 December 2012, accepted 21 December 2012.

Correspondence: Dr. Emylian A. Ivanov, Department of Anatomy, Histology and Cytology, Faculty of Medicine, Medical University-Pleven, 1, Sv Kliment Ohridski Str., BG-5800 Pleven, Bulgaria. Tel. +359-64-884 240,

E-mail: ahcb@mu-pleven.bg 
of afferent innervation. Approximately $90 \%$ of all cochlear afferents project to individual IHCs via thick unbranched radial afferents, which terminate at a single synapse. The OHCs, on the other hand, receive a more diffuse innervation from a relatively few thin spiral afferents, along the length of cochlea before branching to contact 5 to 50 hair cells. The active zone is demarcated by a slight thickening of the plasma membrane, and a collection of synaptic vesicles associated with the synaptic ribbon (2,3). Even in the absence of stimulation, the hair cell ribbon-type active zone evokes "spontaneous" spiking in the afferent neuron at rates of up to or even beyond $100 \mathrm{~Hz}$ (4-6). In order to ensure such a remarkable temporal fidelity and high throughput, the hair cell afferent synapse possesses unique molecular and structural specializations, some of which have been elucidated only recently. Mature afferent hair cell synapses usually display one single synaptic ribbon or synaptic body facing one postsynaptic density. Ribbons tether a monolayer of synaptic vesicles, with a high packing density (7). A fraction of these ribbon-associated vesicles "docks" onto the presynaptic membrane. In addition, some docked vesicles are not associated with the ribbon, and some cytosolic vesicles neither make contact with the presynaptic membrane nor bind to the ribbon. The synaptic vesicles that populate the hair cell active zones comprise only a tiny fraction of the large number of synaptic vesicle pool contained in a hair cell (8).

The main role of the inner hair cells is to transmit auditory signals to the central nervous system (CNS). $95 \%$ of the auditory afferent nerve fibers, that transmit sound information to the brain, contact only the IHCs. Therefore the synapse between the IHC and afferent fibers represents the first relay station in the auditory pathway as most of the sound information has to pass through it. The OHCs receive about $5 \%$ of the afferent innervation. Not much is known about the function of the afferent fibers in this sensory compartment (9).

\section{AFFERENT INNERVATION OF THE COCHLEA}

The afferent innervation of the hair cells in the mammalian organ of Corti is provided by two distinct neural systems, which transmit the sound information to the CNS. The IHCs and OHCs are innervated by diverse populations of afferent cochlear neurons that differ in their cellular morphology and dendrite arborization patterns in the cochlea. The IHCs are innervated by the type I spiral ganglion neurons (SGNs); the latter are characterized by myelinated bipolar perikarya and thick unbranched and radially oriented dendrites. Each of the approximately 850 IHCs in the cochlea of the adult rat is in- nervated by 20-30 type I ganglion cells, i.e. 90-95\% of the total neuronal population of the spiral ganglion (10). The OHCs are innervated by the type II SGNs. The latter are pseudounipolar, have non-myelinated perikarya and thin dendrites which branch spirally to make synaptic contacts with 5 to 50 hair cells. These comprise $5-10 \%$ of the whole SGN population and supply about 2000 OHCs (11-15).

The afferent synapses of the hair cells convey faithful and reliable information for the frequency composition, intensity of sound and localization of sound sources in space via registration of the interaural difference in the range of milliseconds. They also record the changes in the background noise regardless of the adaptive mechanisms of the auditory sensory system. In order to carry out sound transmission, the afferent synapses are equipped with unique cellular and molecular specializations.

The presynaptic active zone is morphologically defined as a site where the synaptic vesicles concentrate, anchor and fuse with the presynaptic membrane, and physiologically is the site of neurotransmitter release. Opposite the active zone the postsynaptic thickening is to be found. The high electron density on both sides of the synaptic cleft is indicative of the protein nature of these specialized sites. The active zone is neighbored by the presynaptic zone where, after the fusion with the presynaptic membrane, the synaptic vesicles are renewed by clathrin-mediated endocytosis (17).

A striking peculiarity of the presynaptic zone in these synapses is the presence of electron dense structures resembling ribbons, and such synaptic contacts are called ribbon synapses (18). The patterns of the ribbon synapses are summarized by Lenzi and von Gersdorff (19).

The synapses with a low rate spontaneous activity are localized on the modiolar side of IHCs and are characterized with larger ribbons than these with a high spontaneous rate, which are localized on the side of the pillar cells (20).

The synapses between the OHCs and non-myelinated spiral fibers of the type II SGN do not possess synaptic bodies in the cochlea of the rat. Such are observed solely in the apical turns in the guinea-pig and humans (19). The dense synaptic ribbons display spherical, ellipsoid or laminar shape ranging from 0.1 to $0.4 \mu \mathrm{m}$ in length depending on the species, cellular type, stage of development and position within the presynaptic bouton (19).

The synaptic bodies in adult animals are usually solitary structures. In the mature sensory cells, a synaptic ribbon anchors to the plasma membrane of one active zone. A small 
number $(<5 \%)$ of ribbons comprise the so-called "floating" ribbons which probably reflect a state of exchange $(21,22)$. The shape, size and number of ribbons differ in accordance with the tonotopic axis, the various periods of development and even amongst the different active zones. For example, the diameter of a synaptic body grows larger along with the increase of the frequency characteristics of a cell.

The close apposition of the synaptic body to the presumable site of transmitter release and its association with the synaptic vesicles is indicative of its role in synaptic transmission. Ultrastructural data in the developing cochlea show that the dense bodies form in the cytoplasm and then migrate to the basolateral membranes, where they initiate the formation of synaptic specializations. Opinions exist about the role of the synaptic ribbon as a conveyor belt that actively moves vesicles toward their release sites or a safety belt that tethers vesicles stably in mutual contact and thus facilitates multivesicular release by compound exocytosis (23).

A monolayer of vesicles completely encircles the synaptic body and is only discontinued at the sites of presynaptic thickenings. The synaptic vesicles are anchored to it via fine threads, i.e. they are 'tethered'. These ribbon-associated vesicles are a small fraction of the large number of synaptic vesicles which are in the hair cell. The number of docked vesicles in a mouse IHC ranges from 100 to 200 (24).

The synaptic vesicles represent a heterogeneous population. The ones beneath the synaptic body are round, small and relatively uniform while those covering the vesicles are round or flattened and of a varying size (25). At the hair cell ribbon synapse Nouvian et al. (26) morphologically distinguished three vesicle populations: (i) docked vesicles; (ii) ribbonassociated vesicles; 3 ) free cytosolic synaptic vesicles.

Docked vesicles at a conventional synapse are viewed as a homogenous pool; however in the hair cells they are found in a variety of spatial positions including just underneath the ribbon (docked and ribbon-associated vesicles) or at the active zone without contacting the synaptic body (7). As a whole, the vesicles at the active zones comprise a small part of the synaptic vesicles. The proximity of the docked vesicles to the calcium channels at the active zones denotes their functional importance.

Both types of the docked vesicles constitute a vesicle pool called readily releasable vesicle pool (RRP) which could sustain exocytosis for a period of a few seconds. The recorded spontaneous and long-lasting neurotransmitter release from the hair cells would require mechanisms for the fast and effective renewal of RRP. During a long-lasting potassium depolarization of the saccular receptor cells in the frog, a dramatic decrease in the number of docked vesicles is observed. Conversely, far fewer are the affected vesicles docked at the opposite pole of the synaptic bodies, which supports the hypothesis that they are also involved in the vesicular release (22).

Important components of the synaptic composition are the filaments that tether the synaptic vesicles to the synaptic body. Unlike the conventional synaptic contacts where the binding to synaptic vesicles is provided by synapsin I, the ribbons contain kinesin which facilitates the fast transport of the synaptic vesicles toward the synaptic membrane via an unknown mechanism. There are also speculations that during exocytosis the filaments depolymerize and then repolymerize during the vesicular renewal. Osborn (27) suggests that there exist filamentous connections not only between the electrondense bodies and the vesicles but also between the vesicles themselves.

The presynaptic membrane is electron dense and usually smooth. Ultrastructural observations of the synapses reveal a network-like structure of the presynaptic grid consisting of regular rows of electron-dense and conical in shape particles, which extend about $50 \mathrm{~nm}$ into the cytoplasm. The cones are interconnected by a meshwork of cytoskeletal filaments that extend deeply into the presynaptic bouton. Unlike the discrete presynaptic thickenings, the postsynaptic ones are continuous and are observed throughout the synapse.

Two morphologically distinct types of terminals, which make a contact with the IHCs, have been described. The first type comprises endings with a conventional bouton-like morphology, designated as classical terminals. The second type includes larger nerve endings, whose membrane is deeply folded (28). This membrane fold creates an incomplete partition, oriented parallel to the IHC membrane which partially divides the terminal in two compartments: an inner one that is postsynaptic to the IHC and an outer one which is sometimes postsynaptic to the vesicular efferent endings. The axodendritic synapses involve the outer segment, most often in regions with a frequency of $8 \mathrm{kHz}$. It is assumed that the partition isolates the afferent from the efferent synaptic activity and influences the metabolic activity. The decrease in the mitochondrial number in the inner compartment of the terminal could be associated with a glutamate-induced excitotoxic damage and indicates age-related functional disturbances $(29,30)$.

It is proposed that the folded endings have undergone pathological alterations or degeneration. There is still doubt 
about their origin, since the terminal stages of dendrite degeneration have never been observed. The variations in their size, shape and positioning could be due to differences in their physiological activity.

In our experiments on the afferent innervation of the IHC in the rat, no folded endings were found.

\section{Molecular composition of the ribbon synapses}

As a whole, the molecular composition of the ribbon synapses is similar to that of the conventional synapses in spite of the unique isoforms of the synaptic proteins (19). The only exception is the protein family of synapsins and synaptotagmins I-II. Synapsins decrease the vesicular transport through attaching to the actin cytoskeleton and their absence is of functional significance for the synaptic kinetics. Synaptotagmins I and II have regulatory roles in the synaptic vesicle docking on the presynaptic membrane. The high rate of transmitter release is another notable difference from the conventional synapses (31). The immunolocalization of several proteins, which could be components of the synaptic body, has been observed. The homology between the retinal and IHC ribbon synapses reveals an identical molecular composition. Indeed, the synaptic bodies of these two cellular types contain the RIBEYE, Bassoon and Piccolo proteins (22). It is thought that the RIBEYE is a structural component of the ribbon which has an enzymatic activity at the synapse. The Bassoon and Piccolo proteins are large cell-matrix molecules which are involved in the anchoring of the synaptic bodies at the active zones. The deletions of Bassoon genes result in a lack of such synapse-anchored ribbons (22). In addition, a reduced current in the IHC is observed, which reflects defects in the insertion of the calcium channels resulting from a damage of the Bassoon molecules. The Piccolo proteins are considered to be $\mathrm{Ca}^{2+}$ sensors at the synapse whose affinity for calcium designates them as the main source for its renewal following multiple stimuli.

In the active zone of the cell matrix a few more groups of proteins are reported (32-35). The first group of proteins is involved in the fusion of synaptic vesicles, vSNARE, SNAP25, syntaxin, Munc, RIM and ELK. They participate in the formation, release and renewal of the synaptic vesicles and also regulate the events during the short- and long-term synaptic plasticity. The second group includes cytoskeletal proteins, e.g. actin, tubulin, myosin, spectrin and $\beta$-catenin. The third protein group consists of cell-adhesion molecules such as neurexins, cadherins, integrins and sidekicks. The last group involves calcium-dependent channels.

\section{Calcium channels and neurotransmitter release}

It is well-known that the synaptic transmission at the IHC afferent synapses is glutamatergic. Conversely, less is known about transmission from OHCs to type II afferents. The specificity of the hair cells to continuously and rapidly release their transmitters requires a unique configuration of their ion channels, receptors and transporters on the pre- and postsynaptic membranes of the afferent synapses. Closely apposed to the ribbons are calcium channels (KCNJ10 and KCNQ4), complexes of voltage-gated calcium channels (VGCCs) and BK-type (calcium sensitive) voltage-gated potassium channels. Upon the postsynaptic membranes of the sustentacular cells, which surround the IHCs and the afferent synaptic contacts are located AMPA receptors and GLAST glutamate transporters. Following a mechanical stimulation of the stereocilia, the apical $\mathrm{K}^{+}$influx leads to depolarization of the hair cells and activation of VGCCs which in turn causes the opening of the BK-channels. It is believed that the synchronized interaction between the VGCCs and BK-channels is critical for the effective glutamate release.

The coupling of a stimulus and transmitter release could be explained with the existence of control mechanisms for the synaptic vesicular exocytosis via the presence of calcium microdomains and nanodomains (36). Synchronizing of the synaptic transmission occurs via the involvement of the RRP. The ribbon stabilizes a large number of RRP and facilitates the release of several vesicles in a short time in each active zone (22). Thus, a multiple exocytosis with a high level of synchronization occurs. Unlike the calyx of Held in the CNS, which conveys impulses with high reliability and precision in time and act in numerous small active zones, the ribbon synapse operates in a single active zone but with a large number of the RRP. The short-term partial RRP depletion most probably reflects the process of auditory adaptation and the peripheral processing of complex sound signals (37).

The presence of various types of calcium channels (38) suggests their effectiveness in certain time and space and their role in different cellular functions (39). These hypotheses were created to suggest the presence of a calcium microdomain, requiring a calcium-sensitive area with a molecular distance from the site of transmitter release (40). Interacting protein domains of the calcium channels and the proteins involved in membrane fusion are the basis of such interactions (41). The microdomain model provides a reliable insight in the fast synaptic transmission and a suitable mechanism for a rapid onset of the neurotransmitter release; in cases it is combined with 
a calcium receptor with a low affinity it can cause an abrupt stop of the process. An important issue for the regulation of neurotransmitter release are the fixed and mobile calcium buffers which bind to the inflowing calcium and in that way let only a small fraction (1-2\%) from the overall calcium to be involved in the onset of exocytosis. The mobile buffers bind calcium and diffuse to distant cellular compartments. The fixed buffers also bind calcium but remain in a dynamic equilibrium with the microdomains and are responsible for the gradual elevation of the calcium levels (42).

Little is known about the cellular and molecular events that follow the calcium binding. The combination of calcium and exocytosis in fast neurotransmission in the range of 1-2 ms allows insufficient time for multiple protein-protein interactions and conformation changes, and suggests that most of these molecular mechanisms occur before the $\mathrm{Ca}^{2+}$ influx. The synaptic vesicles are at different stages of development regarding membrane fusion which depend on the molecular state of the synapse-associated proteins and that of the fusion sites $(43,44)$. Following the vesicular fusion their content is discharged in the synaptic cleft and probably reaches certain millimolar levels of concentration before binding to the postsynaptic receptor. The transmitter state is determined by the activity of the degrading enzymes and the transport mechanisms directed at the presynaptic terminal and the neighboring glial cells (45).

\section{Physiology of the ribbon synapses}

The cochlear hair cells convert the sound vibrations into equivalent voltage waves. These receptor potentials evoke transmitter release from SGN whose axons project to the CNS. In the IHCs, the monosynaptic contact is made up of an individual SGN and the single presynaptic specialization, the so-called dense body or ribbon $(14,46,47)$. Therefore, each synaptic ribbon performs a specific signal task. The intensity and duration coding are critical for the binaural interactions during sound localization (48).

The transmitter release in the cochlea of the postnatal rat has been investigated via records of the excitatory postsynaptic currents (EPSCs) from the afferent boutons, which are in a direct contact with the ribbon synapses. These records provide evidence that the ribbon synapses operate through a multivesicular release in order to attain high-frequency transmission. The small size of the contacts in the zones of the ribbon synapse shows that the EPSCs most probably arise from single presynaptic active zone, usually involving one or two synaptic ribbons. Prior research has found that the IHCafferent synapses operate via AMPA receptors. The work of Glowatzki and Fuchs (49) shows that the EPSCs are mediated only via AMPA. Throughout the auditory pathway, the AMPAmediated ion currents possess fast kinetics and therefore such could be expected in the IHC synapses. There remains the issue of how the ribbon synapses maintain a fast and continuous transmitter release. Most researchers support the hypothesis for a multivesicular release. Based on the ultrastructural data from ribbons it seems that a multivesicular release occurs simultaneously. When reconstructing the synaptic zones it has been shown that 138 dense-cored vesicles are found underneath the ribbon, in a diameter of $470 \mathrm{~nm}$ in the receptor cells of the saccular macula. In the IHCs, the ribbon tends to be smaller and the diameter of the zones is 100 to $250 \mathrm{~nm}$, while the maximal vesicular number is about 20. When measuring the resistance it has been proved that the maximum speed of release is about 250 vesicles/sec.

The synaptic physiology is investigated with a couple of basic techniques, namely patch clamp recording of the membrane resistance, which changes upon fusion of the synaptic vesicles, and recordings of the cochlear nerve activity. The patch clamp recording technique permits membrane current measurements $\left(\mathrm{C}_{\mathrm{m}}\right)$. Upon fusion of the synaptic vesicles with the plasma membrane the cell surface increases, and therefore $\mathrm{C}_{\mathrm{m}}$ also increases. This method allows to indirectly investigate the presynaptic function. Following depolarization of the IHCs, the $\mathrm{Ca}^{2+}$ influx across the Cav1.3 L-type calcium channels triggers the exocytosis of the RR synaptic vesicles. Depending on the duration and intensity of the stimulus, the $\mathrm{C}_{\mathrm{m}}$ increase is a result of exocytosis in all active zones, fusion of the synaptic vesicles out of the active zones and even fusion of non-synaptic membrane organelles.

Based on the $\mathrm{C}_{\mathrm{m}}$ measurements, two kinetic components of exocytosis have been found. The first kinetic component comprises the extreme $\mathrm{C}_{\mathrm{m}}$ increase within milliseconds. It is thought that this fast component is indeed exocytosis of a small pool of synaptic vesicles, the so-called RRP, corresponding to the classical functional vesicular pool. The fast component matches the fusion of 5 to 8 synaptic vesicles, at a maximum speed of 2000 per second in each of the 25 active zones of IHCs in the apical cochlea of a mouse. Such a high initial speed of vesicular fusion complies with the highest triggering frequency of the cochlear nerve (50). It is believed that this RRP corresponds to the docked vesicles at the sites of $\mathrm{Ca}^{2+}$ influx in the active zones. The synaptic vesicles are in a close spatial 
contact with the calcium channels, which are concentrated at the receptor active zones. According to Brandt et al. (51) such relationships facilitate the nanodomain control upon the synaptic vesicle exocytosis. Studies on the fast component assess the dynamics of depletion and reload of tethered synaptic vesicles. The synaptic recovering results from short-term adaptation, which depends on the adequate reloading of the ribbon with vesicles from the cytoplasmic pool. Such a phenomenon shows the functional difference between the synaptic ribbons in the auditory and visual systems.

The second kinetic component is slower (10 msec to 1 sec) and is triggered by prolonged stimuli. Then, the $\mathrm{Ca}^{2+}$ levels in the cell increase. This cannot be provoked by weak and varying in time and amplitude stimuli. This component takes place at a time when the calcium channels are resistant, which permits the influx of a significant amount of $\mathrm{Ca}^{2+}$ into the cell. This slower kinetic component comprises the fusion of cytoplasmic vesicles with the sites of release and reflects the importance of remote calcium signaling (52). There are three possible mechanisms explaining the slow kinetics. The first one includes attaining competence for fusion of the synaptic vesicles. The second consists of the RR vesicular fusion at sites that are remote from the calcium channels. The third mechanism includes the fusion of RR vesicles close to calcium channels with a varying affinity to $\mathrm{Ca}^{2+}(53)$. Related to the exocytosis kinetics, literature data suggest a hypothesis according to which in the first component the RR vesicles docked in the active zone or ribbon-associated vesicles are involved, while the second component includes the renewal of the non-docked ribbon-associated vesicles. It is assumed that the second kinetic component of exocytosis comprises a serial renewal of RRP, and also parallel exocytosis at 'ectopic' sites of fusion.

Recordings of membrane resistance provide information about the increase or decrease of surface, related to the vesicular release and vesicular renewal. Research on hair cells shows that these vesicles are capable of performing transitory and prolonged membrane fusion (50). Studies suggest that the docked vesicles are released first, and afterwards there is a movement of the rest of them along the ribbon and a synchronous renewal of the loaded vesicles. The last stage also occurs with a free diffusion of vesicles, which is independent of $\mathrm{Ca}^{2+}$. Therefore, if a ribbon serves as a store for vesicles close to the fusion sites (active zones), the process of the docked vesicle renewal happens relatively fast. Quite a large number of vesicles can fill in the so-called docking sites underneath the ribbon, although the vesicle-active zone interactions are hap-hazardous and independent of the calcium levels. This complies with the calcium-independent positions of the SNARE complex (54).

These methods allow the tracking of RRP dynamics. The RRP exocytosis is fast, with a period of saturation up to 50 msec, followed by a fast renewal of about $200 \mathrm{msec}$. The longer depolarization ( $<250 \mathrm{msec}$ ) evokes a second and slower kinetic component of exocytosis.

The process of adaptation is a common trait of the sensory systems, and it is characterized with a decrease in sensitivity during a lasting and permanent stimulation. Adaptation in the peripheral auditory system is within milliseconds. It is localized in the hair cell afferent synapses which cannot maintain the cellular receptor potentials at prolonged acoustic stimulation (55). Exocytosis at the ribbon synapses displays multiple kinetic components. Such components are determined by discernable vesicular pools typed by their molecular exocytotic pattern, or periods of time for transfer from various localizations to the sites of transmitter release.

Multiple kinetic components are reported during the exocytosis in mouse IHCs (52). The depletion of RRP in the fast component is a way of neuronal adaptation. In such cases, adaptation reflects the depletion of tethered vesicles, while recovery after adaptation reflects the reloading of the ribbon with new synaptic vesicles.

The study of Spassova et al. (37) supports the notion that the depletion and renewal of RRP facilitates short-term adaptation of the cochlear nerve in adaptation recovery. The rapid release or the slow component in exocytosis has been observed in columnar hair cells in birds. Adaptation and its recovery during sound-provoked and spontaneous activity are also fast and follow a course similar to the depletions and renewal of RRP.

\section{Development of afferent innervation}

The development of afferent innervation begins early, even before the morphological differentiation of the hair cells. An invasion of afferent fibers in the undifferentiated cochlear epithelium has been shown in vivo in mice $(56)$, rats $(57,58)$ and in the human fetus (59). In particular, filopodia-like endings making multiple contacts with hair and sustentacular cells, ectopic presynaptic bodies and vesicles of different size in the postsynaptic terminals are seen (60).

The role of afferent fibers for the initiation of cell differentiation in the receptor epithelium is arguable $(61,62)$. It is believed that they have impact very early in the differentiation of the hair cells. In experiments with a deprivation of 
the spiral ganglion the cells do not express $\mathrm{B}$ and $\mathrm{H}$ antigens which are surface cell glucoconjugates and specific markers for cell differentiation (61). Although at the time it is difficult to distinguish between type I and type II endings, there is indirect evidence for the fiber origin in ototoxic experiments or in a direct visualization with specific markers.

In the cochlea of the adults, the excess of glutamate causes acute and specific damage of the type I neuron's dendrites, a phenomenon known as excitotoxicity. The same effect is seen after treatment with kainic acid which blocks the glutamate receptors of the type I neurites (63). The spiral afferent endings of the type II neurons do not change their structure and remain intact (63). Studies on the rat cochlea treated with kainic acid show that the OHCs are innervated at the early stage by the same type of kainic acid-sensitive dendrites as the IHCs. These are branches of the radial dendrites of the type I neurons. The thin afferent fibers with a denser cytoskeleton are spiral dendrites of the type II neurons and they provide a continuous afferent innervation of OHCs. These fibers do not react to kainic acid. Such a transitory type I innervation of OHCs has been demonstrated by means of impregnation with horseradish peroxidase (HRP) (63).

The transitory innervation of OHCs has been shown in studies with HRP in gerbils (64) and hamsters (65). HRP is used for studying the postnatal modification of neuronal projections to the both types of hair cells in mammals. These results confirm earlier data stating that the model of neuronal branching in the region of IHCs and OHCs is fundamentally different. The neuronal branches associated with the IHC initially make contacts with several hair cells and then they form punctuate bouton endings with an individual hair cell. The sprouting progressively increases in the direction of the $\mathrm{OHC}$ and contacts with an ever-larger number of hair cells. At birth the radial afferents in the cochlea make contacts with both types of hair cells (61). It is still to be elucidated whether at the stage of branching the early radial afferent fibers reach the OHCs. According to the classical studies of Retzius (66) and Lorente de No (67) these fibers innervate both types of hair cells although these authors do not provide evidence for discrimination of the SGN types. Gil-Loyzaga and Pujol (68) clearly demonstrate that the OHCs are innervated at an early stage by the same type of kainic acid-sensitive dendrites as the IHCs, thus confirming the transitory radial innervation of these cells.

Such a budding of radial afferents has also been shown with the Golgi impregnation (69). During development this primitive stage of branching has also been seen under the transmission electron microscope (TEM), and it is followed by a stage of pruning. In adults this model of branching of the radial dendrites is observed in the extreme apex of the cochlea and is thought a pattern of immaturity (70) or is seen during regeneration of the radial dendrites following excitotoxic damage (71). The temporary radial afferent branching upon the immature OHCs disappears right before the initiation of their motility function and overlaps with the formation of the medial afferent synapses (72). It seems that the regression of the radial afferents on the OHCs does not entirely depend either on the advance of the efferents or on the beginning of the sound-initiated activity (64). The regression is most probably determined by inner changes in the OHCs associated with their differentiation, which at the earlier stage of development resemble the IHCs and then become a sensor-motility type of cells.

The onset of the cochlear function is at various ages in the different species - in the chicken in the last gestation week (73), and in the rodents during the second postnatal week (74). In this period, the hair cells undergo dramatic changes regarding their electrophysiological patterns. This is the stage of continuous alterations in the synaptic morphology although little is known about the onset of neurotransmitter release by the hair cells. The functional maturation of audition is preceded by a period of spontaneous activity. This stage is significant for the development and enhancement of the synaptic contacts $(75,76)$.

We followed up the early and late stages in the development of the afferent innervation in the rat by using TEM. In the period of P0-P3 the IHCs and OHCs can be clearly distinguished from the sustentacular cells. On their basolateral membranes synaptic contacts with different by nature nerve fibers are seen. Many of these fibers and terminals are free and in close proximity to the cell base without establishing synaptic contacts. In the synaptic area of the IHCs, many afferent and efferent nerve fibers are found. The endings of the afferent fibers are large, cover most of the synaptic areas of the IHCs and contain smooth cisternae and cytoskeletal elements. They form finger-like projections which enhance the contact with the hair cells. This morphological pattern is thought to be indicative of immaturity (Fig. 1A, B). The synaptic contacts between the afferent endings and the plasma membrane of the IHCs are characterized by symmetrical thickening of the pre- and postsynaptic membranes. The efferent nerve fibers are thin and multiple, and terminate with small bouton-like 


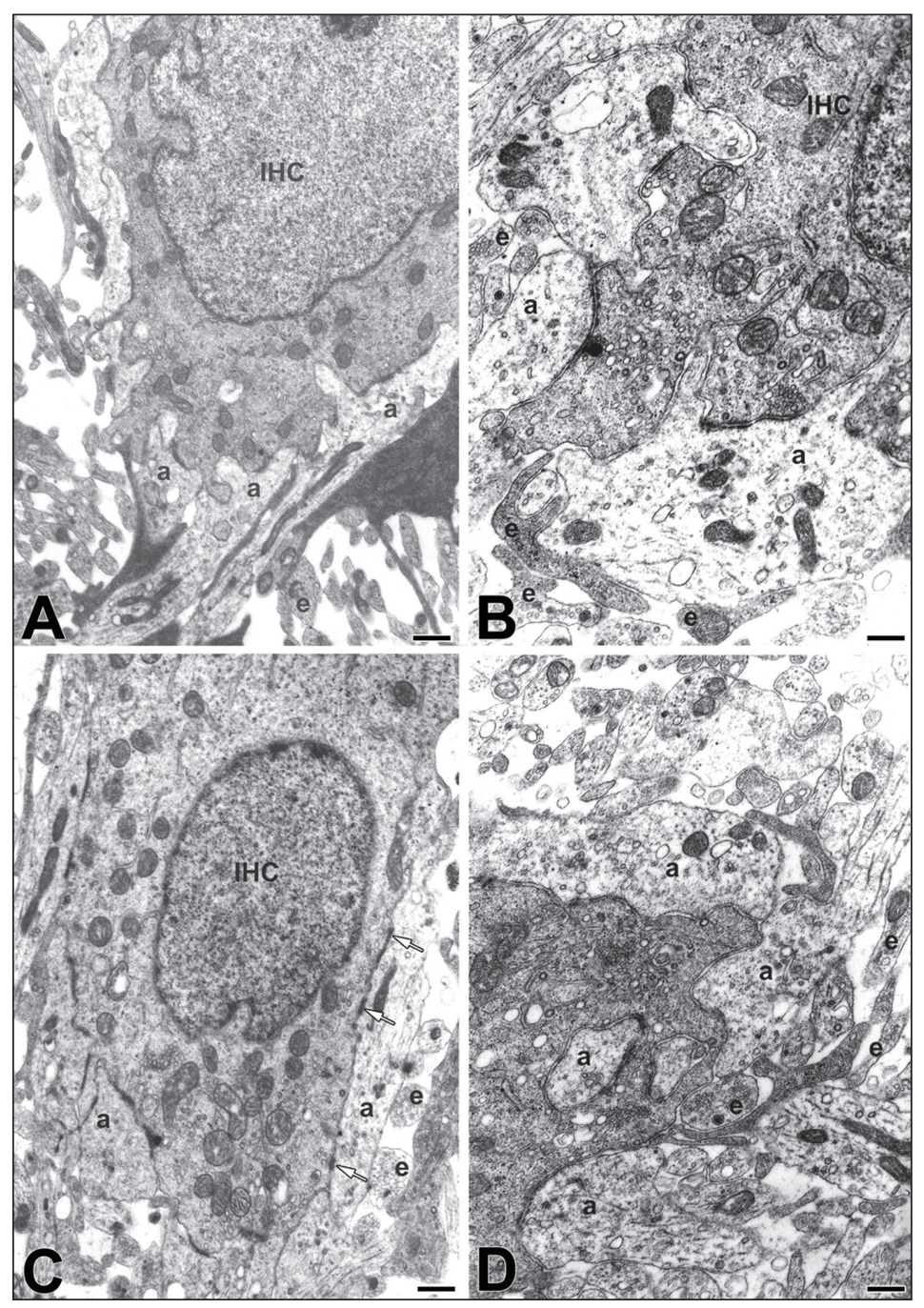

Figure 1. Pattern of the afferent innervation on postnatal days 0 to 3 (P0-P3). (A) At P0 stage, afferent fibers and terminals on the basolateral surface of an inner hair cell (IHC) forming finger-like projections with symmetrical pre- and postsynaptic thickenings are observed. Also note below some profiles of small-caliber nerve fibers which are presumable efferents (e) and do not make synaptic contacts. (B) Large afferent terminals (a) with finger-like projections are also seen at $P 3$ stage. (C) An IHC that is contacted by afferent terminals (a). Note that an afferent nerve ending may also appear as a bouton "en passant" making multiple synaptic contacts (arrows) on this cell. (D) At this stage, the basal compartment of the IHC is not only contacted by afferent boutons (a) but also by small efferent boutons (e) containing numerous small clear vesicles and a few larger dense-cored vesicles. Scale bars $=0.25 \mu \mathrm{m}$ in $(\mathrm{A}, C), 1 \mu \mathrm{m}$ in $(B)$ and $0.75 \mu \mathrm{m}$ in $(D)$. endings containing synaptic vesicles (Fig. 1C, D).

Two types of nerve fibers with different ultrastructural patterns are found in the synaptic area of the OHCs. The first type of nerve fibers is of a larger caliber, and they possess a loose arrangement of their microtubules and neurofilaments. The second type is thinner, of a smaller caliber and has a relatively dense arrangement of the cytoskeletal elements. Usually they are situated deeper in the interstitium, among the Deiters cells. Synaptic spines of afferent dendrites of both types of fibers form somatodendritic synapses with a symmetrical morphology. The active zone is equally dense and encloses a narrow synaptic cleft with electron-dense material (Fig. 2).

In the cochlea of younger animals at P0-P3 dominate ribbons with round profiles. They are connected via short filamentous bridges to the presynaptic membrane. Also, synaptic bodies located free in the cytosol of the hair cells and unconnected with the presynaptic membrane are seen. The ultrastructure of the ribbons is characterized with homogenous or granular content. Out of 115 counted ribbons in the organ of Corti in rats at this age, 26 are found in the IHCs and 89 in the OHCs, corresponding to the ratio of the two cell populations. The largest number of ribbons is observed in the first row of OHCs.

During P4-P5 the afferent innervation of the hair cells changes. The afferent terminals upon the IHCs enlarge and take up a calyx-like shape. They engage the whole basolateral membrane to the area of intercellular contacts (Fig. 3A, B). The ribbons are of distinct configurations, i.e. laminar, fanlike or crest-like. Such with an unusual shape, i.e. wing-like or T-shaped, are also seen. The variations in the ribbon shape during the developmental stage are determined by their way of attachment to the plasma membrane. Typical of the round- 


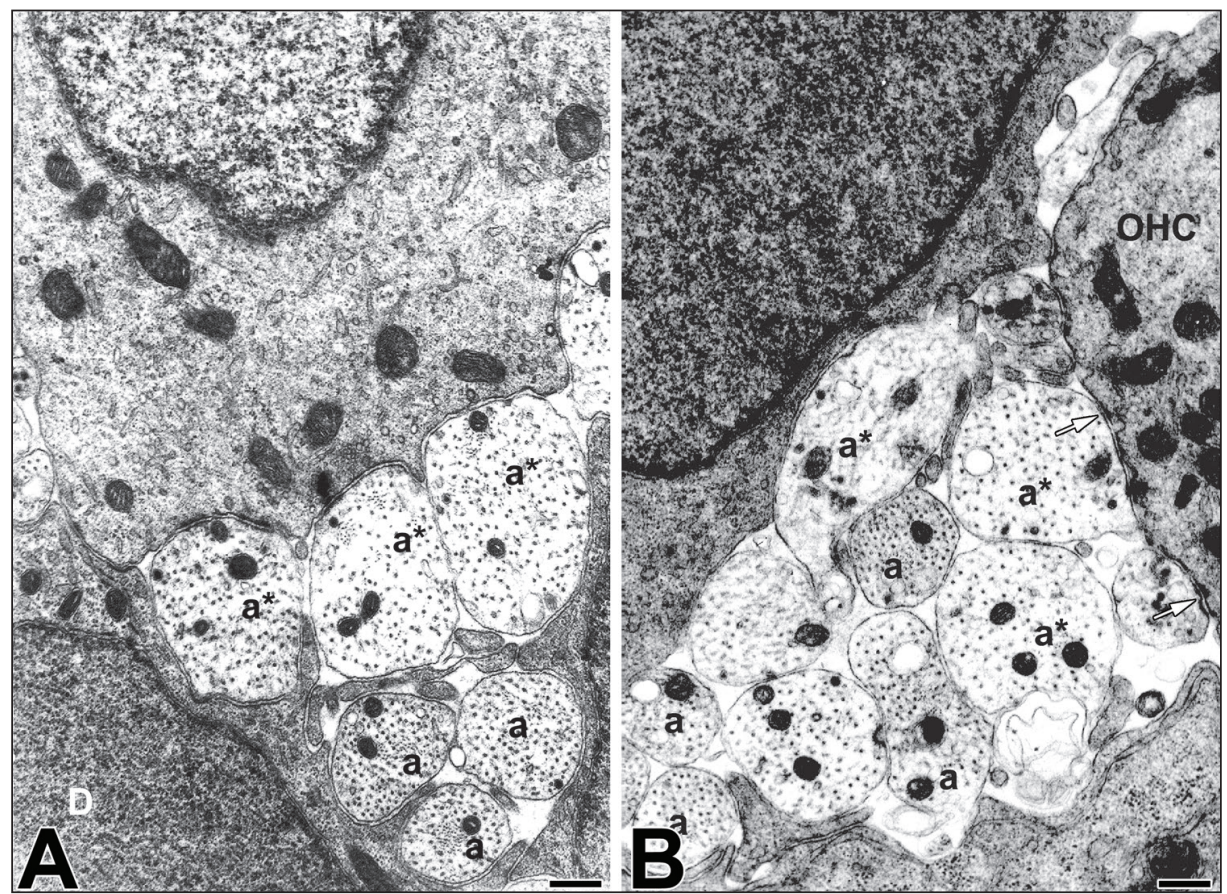

Figure 2. Two types of afferent fibers and synapses on the base of an outer hair cell (OHC). (A) At P0 stage radial afferent fibers ( $\left.a^{*}\right)$ with a large diameter and loose arrangement of microtubules and neurofilaments, and spiral afferent fibers (a) with a small diameter and dense arrangement of the cytoskeleton are seen between the Deiters cells $(D)$. (B) Somatodendritic synaptic contacts (arrows) between the OHC and the dendrites of the two types of afferent fibers, type I ( $\left.a^{*}\right)$ and type II (a) are noted at P3 stage. Scale bars $=0.75 \mu \mathrm{m}$.

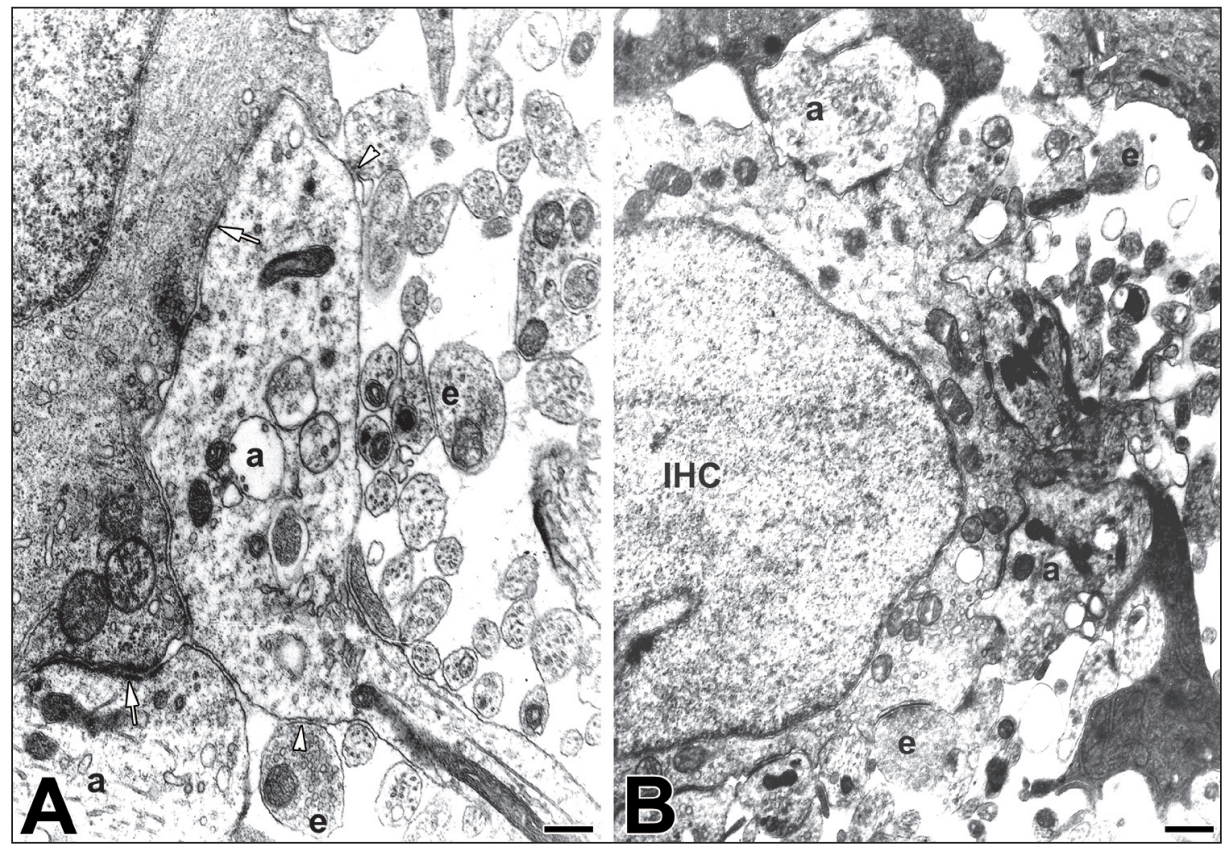

Figure 3. Pattern of the afferent innervation at P5-P7 stage. (A) Calyx-like afferent dendrites (a) forming somatodendritic synapses (arrows) with the basal surface of an IHC. Bouton-like efferent endings (e) some of which make axodendritic synaptic contacts (arrowheads) are also visible. (B) Axosomatic and somatodendritic spinous synapses on an IHC at P7. Scale bar $=1$ $\mu \mathrm{m}$ in (A) and $0.75 \mu \mathrm{m}$ in (B). 
shaped ribbons is their bond with two triangular presynaptic thickenings, which appear filamentous or tubular. The ribbons with a laminar shape bind via a single arcuate density. Occasionally the central region of the rod-like ribbons is bound to the presynaptic thickening via two fine fibers.

During the developmental stage of a synapse, several ribbons could be involved and they form clusters on a restricted area (Fig. 4). The multi-ribbon synapses usually possess a single postsynaptic thickening with intermingling synaptic vesicles. It is thought that they are intermediate stages of the developmental process. With age the ribbons become rod-like, longer and with distinct lamination. The electron-dense lamellae are parallel to the long axis of the ribbon, their number varies and is always larger than three. An age-dependent trait is the appearance of fenestrated or ring-like ribbons which are considered to be an intermediate stage of development. During maturation, the ribbons elongate and attach to the presynaptic membrane via arcuate densities. The ratio of the ribbons in the two hair cell populations changes. Out of the counted 120 ribbons at the end of maturation, 67 are found in the IHCs and 53 in the OHCs, that is their number is almost equal.

Both the number and shape of the ribbons changes at the onset of cochlear function. In mice, IHCs contain multiple small-sized ribbons before the onset of cochlear function, and after only a few larger and oval-shaped ones (22). Differences are also observed in the size of the ribbons in cells forming synaptic contacts with fibers of various spontaneous activity and threshold. For instance, the size of ribbons and the number of the associated with them synaptic vesicles increase along with the decrease of the spontaneous velocity of the fibers (77).

The postsynaptic specializations differ in IHCs and OHCs. In both cellular types there are distinct postsynaptic thickenings. In tissue cultures, the pre- and postsynaptic specializations seem to mature at a different rate, but still the develop-
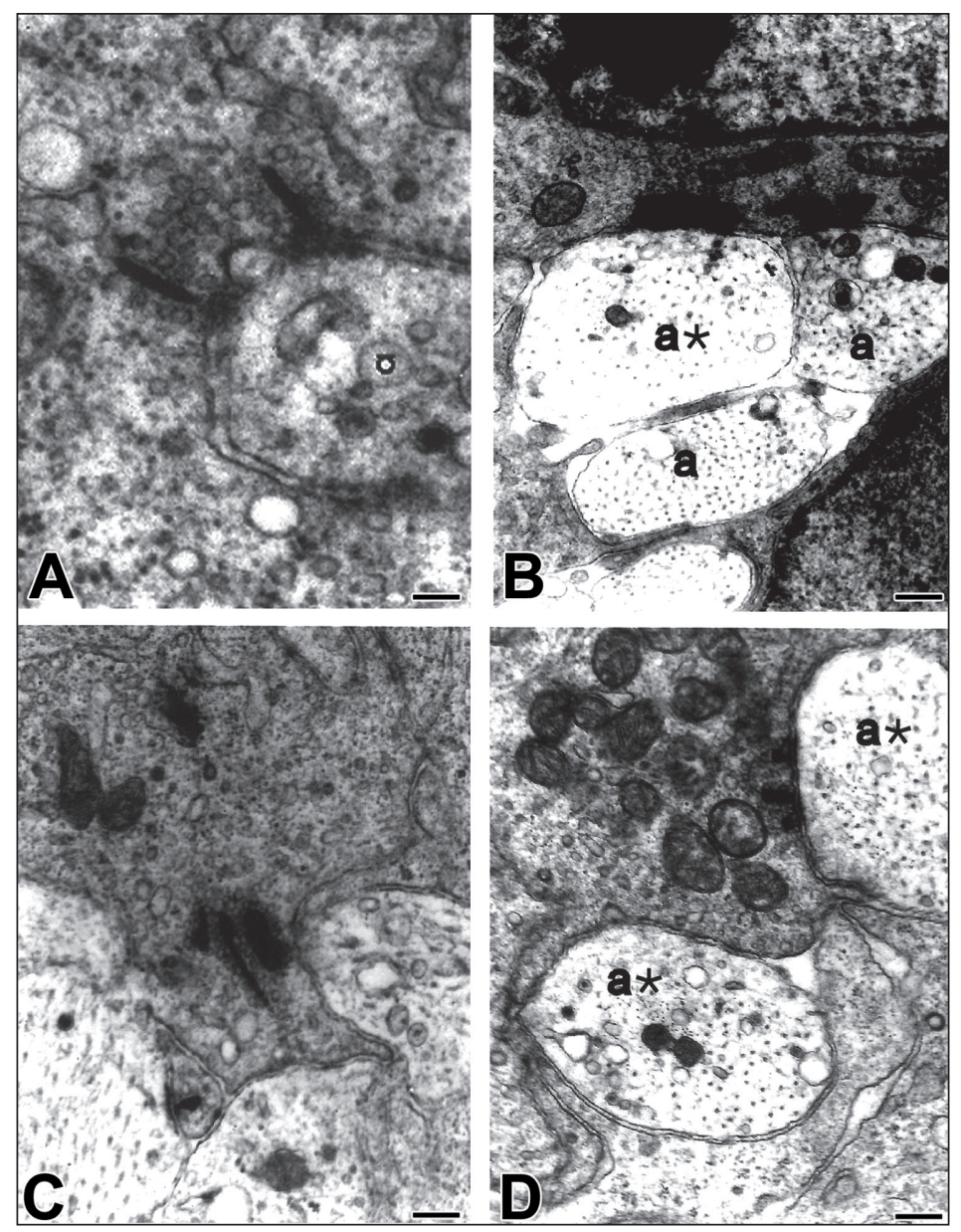

Figure 4. Clusters of synaptic ribbons in the afferent synapses of the IHC (A, B) and $O H C(C, D)$ of various shapes and sizes. $a^{*}$, type I; a, type II afferent fibers. Scale bars $=0.5 \mu \mathrm{m}$. 
ment of the postsynaptic complex is slower. As a whole, the pre- and postsynaptic specializations develop postnatally.

During the late stage of P6-P10 the hair cell innervation undergoes alterations and takes on the patterns of that in the adult. The radial afferent fibers at the base of the OHCs are notably reduced. No large caliber afferent fibers are observed except in the most apical portion of the organ of Corti. They disappear without displaying any preliminary signs of destruction. This overlaps in time with the approach of the efferent nerve fibers which occupy the already freed sites on the plasma membrane. Only the synapses with the thin afferent fibers remain.

In the IHCs the afferent endings retain their prevailing number. Boutons containing synaptic vesicles which make axosomatic contacts or are free in the interstitium are no longer observed, and only these in the axodendritic synapses remain
(Fig. 5A). The ribbons are reduced in number and tend to take on a laminar shape. No configurations of diads and triads are seen. In the presynaptic zone of the IHCs ribbons are only occasionally found. As a rule, in the IHCs a single lamellar synaptic body is involved in the synaptic complex. No multiple active zones are observed either. Thus, each afferent fiber makes a synaptic contact via one active zone and one synaptic body. The above described alterations are considered to be patterns of maturity in the afferent innervation of the IHCs (Fig. 5B).

In the late stage of the cochlear maturation, a reduction in the extensive branching of the radial dendrites to the IHCs is registered. One assumption is that they are displaced by the later coming efferent fibers which invade the cochlea from the brainstem and form axosomatic synapses (Fig. 5C, D). Such a rivalry for a position between the afferent and efferent fibers

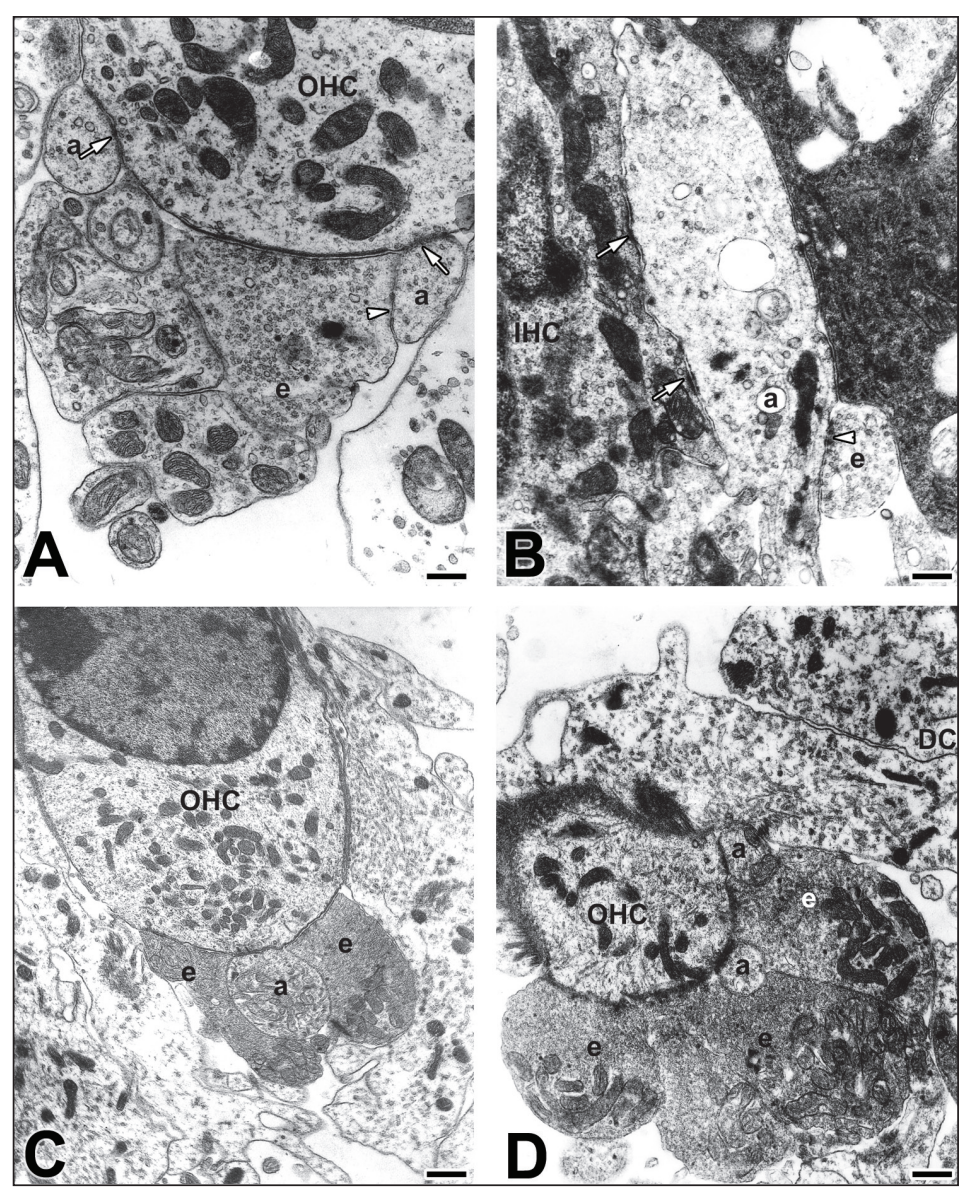

Figure 5. Pattern of the afferent innervation at late stages of cochlear maturation. (A) Somatodendritic (arrows) and axodendritic (arrowheads) synaptic contacts on the basal compartment of an OHC on P7. (B) Somatodendritic (arrow) and axodendritic (arrowheads) synaptic contacts on an IHC on P12. (C) Afferent (a) and efferent (e) synapses on an OHC on P12. (D) Segment of the base of an OHC that is contacted by four large efferent terminals (e) and two small afferent boutons (a). DC, Deiters cell. Scale bars $=0.5 \mu \mathrm{m}$ in $(A, B)$, and $1 \mu \mathrm{m}$ in $(C, D)$. 
seems rather improbable since the penetration of the efferent fibers in the area of the IHCs does not occur before P5, when the afferent fibers have already started to distribute according to the type of the hair cells. Studies on cochlear explants deprived of efferent innervation confirm these findings. An alternative interpretation could be that there is a rivalry for a position between the afferent fibers of the OHCs and the IHCs. It is thought that the first afferents invading the sensory epithelium are the radial fibers and thus they establish preliminary contacts with the IHCs. Perhaps many of these fibers are able to branch and to form morphologically unstable contacts with the OHCs. Later the approaching spiral afferents pass over the IHCs and make stable contacts with the OHCs. It is believed that the multiple processes of the radial afferent fibers to the OHCs are eliminated via selective loss of the unnecessary branches which leads to a strict distribution of the type I neurons to the IHCs and the type II neurons to the OHCs.

The mechanisms through which the afferent fibers of the cochlear nerve are distributed mainly depend on the molecular composition of the synaptic fibers. The synapses on the IHCs at the early stage of cochlear maturation stimulate the auditory pathway via a spontaneous generation of axon potentials. Such a spontaneous activity is observed in the immature auditory pathway of various species and also during the regeneration of the hair cells in chickens (77). This early spontaneous activity is necessary for maintaining the neuronal circuitry. It is promoted by an early and immature model of ion channels (39). During development the calcium channels of the afferent synapses undergo profound changes. The onset of the auditory function is preceded by a period of powerful exocytosis associated with an increased expression of calcium channels. The notable density of calcium channels and the increase in exocytosis lead to the formation of multiple synaptic bodies and active zones as morphological patterns. They peak by the end of the first gestational week and are a typical sign for synaptogenesis in this period. The formation of multiple active zones apposed to a single postsynaptic terminal is necessary for the establishment of the true synaptic configuration. During the late period the number of calcium channels decreases and this reflects the shift from multiple to single active zones, and from spherical synaptic bodies to ribbons. The decrease in the calcium channels is accompanied by augmenting the remaining ones, which most probably rearrange their molecular composition. They become more effective for initiating exocytosis. Probably due to this, the number of synaptic vesicles in the presynaptic zones does not deplete. These channels already possess the ability to transmit sound-provoked potentials.
During development different activity of the two kinetic components of transmitter release has been observed. At the end of the first week, in mice a slow kinetic component is registered which occurs after long-lasting stimuli (200-500 msec). The fast kinetic component is still absent which denotes insufficient harmonization between stimulus and secretion. At the end of the late period the fast component gets activated and a transmitter release is registered after short sound stimuli (50 msec). The effective coupling between stimulus and secretion is of particular importance for strengthening of the bonds with the afferent fibers and the transfer of reliable information at high speed at any moment by the mature afferent fibers.

Both the early and the late stages of afferent maturation are regulated by signal molecules. The signal mechanisms controlling the neurite growth result from factors directing the nerve fibers - neurotrophins, growth factors, morphogenic signals, ephrins and semaphorins $(78,79)$. There is evidence for the role of BDNF, NT3, semaphorin 3A and BRN3a (also known as POU4F1) (80-84). It is thought that the main leading factor for the fibers in the direction of their targets is BDNF which is secreted by the hair cells, although it is also believed that matrix proteins such as semaphorins also take part in this process (84).

It is interesting to note that the fibronectin-like protein, an adhesion molecule which is though to regulate the neurite growth, is transiently expressed in the extracellular space surrounding the IHCs and OHCs in gerbils from P0 to P4. This is the period when the nonspecific afferent branches are formed. The expression of the P2X subunits of the ATP-dependent ion channels in the SGN is in accordance with the afferent synaptic reorganization. The $\mathrm{P} 2 \mathrm{X}$ signaling inhibits the BDNF-induced neurite growth, and therefore it is thought that this is one of the potential mechanisms of neurite control during retraction (85).

\section{CONCLUSIONS}

The neuronal circuitry development of the mammalian cochlea shows common traits which are typical of the whole nervous system and is in general characterized by transient stages of abundant branching, elimination and remodeling of the synaptic contacts.

In particular, the afferent fibers, i.e. the peripheral endings of type I SGN invade the developing otocyst at a very early stage before the recognition of morphologically distinct hair cells. The formation of synapses between the hair cells and the afferents precedes their differentiation and onset of function. The initial synapses are characterized by multiple contacts and numerous presynaptic bodies in the hair cells. This innervation 
pattern of IHCs changes in the course of time. The alterations occur after a transient stage and terminate with an elimination of existent afferent branches. Moreover, some features of the IHC synaptogenesis are also observed in a posttraumatic (excitotoxic) degeneration-regeneration phenomenon of the peripheral processes of SGN.

The maturation events in the OHC afferent innervation pattern are more impressive. In the beginning the OHCs are surrounded by abundant radial and spiral afferent fibers and then they lose their connection with the radial fibers and make contacts with the medial efferent endings. In fact, the OHCs undergo two models of differentiation, a "normal" one that is parallel to the IHC differentiation and a diverse one leading to a cell possessing both sensory and motor features.

In most mammalian species the most apical end of the cochlea retains morphological features of immaturity, particularly pertaining to branching of afferent fibers to the OHCs, presence of multiple ribbons and direct efferent synaptic contacts with the IHCs. All this reflects in the physiological specificity of the apical region, which retains the so-called IHC-like sensory capacity.

\section{ACKNOWLEDGEMENTS}

The authors thank Dr. Angel Dandov for critical reading of the manuscript.

\section{REFERENCES}

1. Fuchs PA, Parsons T. Synaptic physiology of hair cells. In: Eatock RA, Fay RR, Popper AN, editors. Vertebrate Hair Cells, Springer Handbook of Auditory Research, Vol. 27, Springer Science+Business Media, Inc., New York, 2006; 249-312.

2. Spoendlin H. Innervation densities of the cochlea. Acta Otolaryngol 1972; 73: 235-248

3. Berglund AM, Ryugo DK. Hair cell innervation by spiral ganglion neurons in the mouse. J Comp Neurol 1987; 255: 560-570.

4. Kiang NY-S, Watanabe T, Thomas EC, Clark LF. Discharge pattern of single fibers in the cat's auditory nerve. MIT Press, Cambridge, 1965.

5. Liberman MC. Single-neuron labeling in cat auditory nerve. Science 1982; 216: 1239-1241.

6. Brichta AM, Goldberg JM. Responses to efferent activation and excitatory response-intensity relations of turtle posterior-crista afferents. J Neurophysiol 2000; 83: 1224-1242.

7. Lenzi D, Runyeon JW, Crum J, Ellisman MH, Roberts
WM. Synaptic vesicle populations in saccular hair cells reconstructed by electron tomography. J Neurosci 1999; 19: 119-132.

8. Spicer SS, Salvi RJ, Schulte BA. Ablation of inner hair cells by carboplatin alters cells in the medial $\mathrm{K}(+)$ flow route and disrupts tectorial membrane. Hear Res 1999; 136: 139-150.

9. Pujol R, Lavigne-Rebillard M, Lenoir M. Development of sensory and neural structures in the mammalian cochlea. In: Rubel EW, Popper AN, Fay RR, editors. Development of the Auditory System. Springer-Verlag, New York, 1998; 146-192.

10. Mu MY, Chardin S, Avan P, Romand R. Ontogenesis of rat cochlea. A quantitative study of the organ of Corti. Dev Brain Res 1997; 99: 29-37.

11. Spoendlin H. Innervation patterns in the organ of Corti of the cat. Acta Otolaryngol (Stockh) 1969; 67: 239-254.

12. Spoendlin H. Neural connections of the outer hair cell system. Acta Otolaryngol 1979; 87: 381-387.

13. Warr WB, Guinan Jr. Efferent innervation of the organ of Corti: two separate systems. Brain Res 1979; 173: 152-155.

14. Kiang NYS, Rho JM, Northrop CC, Liberman MC, Ryugo D. Hair-cell innervation by spiral ganglion cells in adult cat. Science 1982; 217: 175-177.

15. Pujol R, Lenoir M. The four types of synapses in the organ of Corti. In: Altschuler R, Bobbin R, Hoffman D, editors. Neurobiology of Hearing: the Cochlea. Raven Press, New York, 1986: 161-172.

16. Fuchs PA, Glowatzki E, Moser T. The afferent synapse of cochlear hair cells. Curr Opin Neurobiol 2003; 13: 452-8.

17. Gundelfinger ED, Kessels MM, Qualmann B. Temporal and spatial coordination of exocytosis and endocytosis. Nat Rev Mol Cell Biol 2003; 4: 127-139.

18. Sjostrand FS. Ultrastructure of retinal rod synapses of the guinea pig eye as revealed by three-dimensional reconstructions from serial sections. J Ultrastruct Res 1958; 2: $122-170$.

19. Lenzi D, von Gersdorff H. Structure suggests function: the case for synaptic ribbons as exocytotic nanomachines. Bioessays 2001; 23: 831-840.

20. Slepecky NB, Galsky MD, Swartzentruber-Martin H, Savage J. Study of afferent nerve terminals and fibers in the gerbil cochlea: distribution by size. Hear Res 2000; 144: 124-134.

21. Zenisek D, Horst NK, Merrifield C, Sterling P, Matthews G. Visualizing synaptic ribbons in the living cell. $J$ Neurosci 2004; 24: 9752-9759. 
22. Khimich D, Nouvian R, Pujol R, Tom Dieck S, Egner A, Gundelfinger ED, et al. Hair cell synaptic ribbons are essential for synchronous auditory signalling. Nature 2005; 434: 889-894.

23. Parsons TD, Sterling P. Synaptic ribbon: conveyor belt or safety belt? Neuron 2003; 37: 379-382.

24. Fischer FP. Quantitative analysis of the innervation of the chicken basilar papilla. Hear Res 1992; 6: 167-178.

25. Hama K, Saito K. Gap junctions between the supporting cells in some acousticovestibular receptors. J Neurocytol 1977; 6: 1-12.

26. Nouvian R, Beutner D, Parsons TD, Moser T. Structure and function of the hair cell ribbon synapse. J Membrane Biol 2006; 209: 153-165.

27. Osborne MP. Role of vesicles with some observations on vertebrate sensory cells. In: Cottrell GA, Usherwood PNR, editors. Synapses, Academic Press, New York, 1977; 40-63.

28. Francis HW, Rivas A, Lehar M, Ryugo D. Two types of afferent terminals innervate cochlear inner hair cells in C57BL/6J mice. Brain Res 2004; 1016: 182-194.

29. Goulious H, Robertson D. Noise-induced cochlear damage assessed using electrophysiological and morphological criteria: an examination of the equal energy principle. Hear Res 1983; 11: 327-341.

30. Francis HW, Ryugo DK, Gorelikow MJ, Prosen CA, May BJ. The functional age of hearing loss in a mouse model of presbycusis: II. Neuroanatomical correlates. Hear Res 2003; 183: 29-36.

31. Mandell JW, Townes-Anderson E, Czernik AJ, Cameron R, Greengard P, De Camilli P. Synapsins in the vertebrate retinaabsence from ribbon synapses and heterogeneous distribution among conventional synapses. Neuron 1990; 5: 19-33.

32. Nguyen TH, Balkema GW. Antigenic epitopes of the photoreceptor synaptic ribbon. J Comp Neurol 1999; 18; 413: 209-218.

33. Muresan V, Lyass A, Schnapp BJ. The kinesin motor KIF3A is a component of the presynaptic ribbon in vertebrate photoreceptors. J Neurosci 1999; 19: 1027-1037.

34. Schmitz D, Frerking M, Nicoll RA. Synaptic activation of presynaptic kainate receptors on hippocampal mossy fiber synapses. Neuron 2000; 27: 327-338.

35. Dick O, Hack I, Altrock WD, Garner CC, Gundelfinger ED, Brandstatter JH. Localization of the presynaptic cytomatrix protein Piccolo at ribbon and conventional synapses in the rat retina: comparison with Bassoon. J Comp Neurol 2001; 439: 224-234.
36. Brandt A, Khimich D, Moser T. Few CaV1.3 channels regulate the exocytosis of a synaptic vesicle at the hair cell ribbon synapse. J Neurosci 2005; 25: 11577-11585.

37. Spassova MA, Avissar M, Furman AC, Grumling MA, Saunders JC, Parsons TD. Evidence that rapid vesicle replenishment of the synaptic ribbon mediates recovery from short-term adaptation at the hair cell afferent synapse. JARO 2004: 376-390.

38. Dunlap K, Luebke JI, Turner TJ. Exocytotic $\mathrm{Ca}^{2+}$ channels in mammalian central neurons. Trends Neurosci 1995; 18 : 89-98.

39. Llinas R, Sugimori M, Hilman DE, Cherksey B. Distribution and functional significance of the P-type, voltagedependent $\mathrm{Ca}^{2+}$ channels in the mammalian central nervous system. Trends Neurosci 1992; 15: 351-355.

40. Neher E. Vesicle pools and Ca21 microdomains: new tools for understanding their roles in neurotransmitter release. Neuron 1998; 20: 389-399.

41. Rettig J, Heinemann C, Ashery U, Sheng ZH, Yokoyama CT, Catterall WA, et al. Alteration of $\mathrm{Ca}^{2+}$ dependence of neurotransmitter release by disruption of $\mathrm{Ca}^{2+}$ channel/ syntaxin interaction. J Neurosci 1997; 17: 6647-6656.

42. Roberts WM. Localization of calcium signals by a mobile calcium buffer in frog saccular hair cells. J Neurosci 1994; 14: 3246-3262.

43. Parsons LH, Weiss F, Koob GF. Serotonin-1B receptor stimulation enhances dopamine-mediated reinforcement. Psychopharmacology (Berl) 1996; 128: 150-160.

44. von Gersdorff H, Vardi E, Matthews G, Sterling P. Evidence that vesicles on the synaptic ribbon of retinal bipolar neurons can be rapidly released. Neuron 1996; 16: 1221-1227.

45. Eccles JC, Katz B, Kuffler SW. Effects of eserine on neuromuscular transmission. J Neurophysiol 1942; 5: 211-230.

46. Liberman MC. Morphological differences among radial afferent fibers in the cat cochlea: an electron-microscopic study of serial sections. Hear Res 1980; 3: 45-63.

47. Spoendlin H. Anatomy of cochlear innervation. Am J Otolaryngol 1985; 6: 453-467.

48. Moore DR. Anatomy and physiology of binaural hearing. Audiology 1991; 30: 125-134.

49. Glowatzki E, Fuchs PA. Transmitter release at the hair cell ribbon synapse. Nat Neurosci 2002; 5: 147-154.

50. Parsons TD, Sterling P. Synaptic ribbon: conveyor belt or safety belt? Neuron 2003; 37: 379-382.

51. Brandt A, Striessnig J, Moser T. CaV1.3 channels are es- 
sential for development and presynaptic activity of cochlear inner hair cells. J Neurosci 2003; 23: 10832-10840.

52. Moser T, Beutner D. Kinetics of exocytosis and endocytosis at the cochlear inner hair cell afferent synapse of the mouse. Proc Natl Acad Sci USA 2000; 97: 883-888.

53. Wu LG, Borst JG. The reduced release probability of releasable vesicles during recovery from short-term synaptic depression. Neuron 1999; 23: 821-832.

54. Sorensen JB. Formation, stabilisation and fusion of the readily releasable pool of secretory vesicles. Pflugers Arch 2004; 448: 347-362.

55. Holton T, Weiss TF. Receptor potentials of lizard cochlear hair cells with free-standing stereocilia in response to tones. J Physiol 1983; 345: 205-240.

56. Sher AE. The embryonic and postnatal development of the inner ear of the mouse. Acta Otolaryngol 1971; 265: 1-77.

57. Ivanov E. Postnatal development of the afferent and efferent innervation of the organ of Corti in the rat. Bulg Med 1994; 1-2: 10-16 (in Bulgarian).

58. Gil-Loyzaga P, Merchan-Cifuentes JA. Histogenesis y desarrollo del receptor auditivo. In: Merchan-Cifuentes M, editor. El Oido Interno. Universidad de Salamanca Press, Salamanca, 1982: 85-133.

59. Pujol R. Morphology, synaptology and electrophysiology of the developing cochlea. Acta Otolaryngol (Stockh) 1985; 421: 5-9.

60. Sobkowicz HM. The development of innervation in the organ of Corti. In: Romand R, editor. Development of Auditory and Vestibular Systems, Elsevier, Amsterdam, 1992; 2: 59-100.

61. Pujol R, Lavigne-Rebillard M. Early stages of innervation and sensory cell differentiation in the human organ of Corti. Acta Otolaryngol (Stockh) 1985; 423: 43-50.

62. Gil-Loyzaga P, Remezal M, Oriol R. Neuronal influence on $\mathrm{B}$ and $\mathrm{H}$ human blood-group antigen expression in rat cochlear cultures. Cell Tissue Res 1992; 269: 13-20.

63. Pujol R, Puel J-L, Eybalin M. Implication of non-NMDA and NMDA receptors in cochlear ischemia. NeuroReport 1992; 3: 299-302.

64. Echteler SM. Developmental segregation in the afferent projections to mammalian auditory hair cell. Natl Acad Sci USA 1992; 89: 6324-6327.

65. Simmons DD. A transient afferent innervation of outer hair cells in the postnatal cochlea. NeuroReport 1994; 5:1309-1312.
66. Retzius G. Das Gehörorgan der Wirbeltiere. Samson \& Wallin, Stockholm, 1884.

67. Lorente de No. The sensory endings in the cochlea. $L a-$ ryngoscope 1937; 47: 373-377.

68. Gil-Loyzaga P, Pujol R. Neurotoxicity of kainic acid in the rat cochlea during early developmental stages. Eur Arch Otorhinolaryngol 1990; 248: 40-48.

69. Ginzberg RD, Morest DK. Fine structure of cochlear innervation in the cat. Hear Res 1984; 1: 109-127.

70. Liberman MC, Dodds LW, Pierce S. Afferent and efferent innervation of the cat cochlea: quantitative analysis with light and electron microscopy. J Comp Neurol 1990; 301: 443-460.

71. Puel JL, Saffiedine S, Gervais D’Aldin,C, Eybalin M, Pujol, R. Synaptic regeneration and functional recovery after excitotoxic injury in the guinea pig cochlea. CR Acad Sci III 1995; 318: 67-75.

72. Pujol R, Zajic G, Dulon D, Raphael Y, Altschuler RA, Schacht J. First appearance and development of motile properties in outer hair cells isolated from guinea-pig cochlea. Hear Res 1991; 57: 129-141.

73. Rubel EW. Ontogeny of auditory system function. Ann Rev Physiol 1984; 46: 213-229.

74. Ehret G, Merzenich MM. Auditory midbrain responses parallel spectral integration phenomena. Science 1985; 227: 1245-1247.

75. Jones TA, Jones SM. Spontaneous activity in the statoacoustic ganglion of the chicken embryo. J Neurophysiol 2000; 83: 1452-1468.

76. Jones TA, Jones SM, Paggett KC. Primordial rhythmic bursting in embryonic cochlear ganglion cells. J Neurosci 2001; 21: 8129-8135.

77. Merchan-Perez A, Liberman MC. Ultrastructural differences among afferent synapses on cochlear hair cells: correlations with spontaneous discharge rate. J Comp Neurol 1996; 371: 208-221.

78. Rubel EW, Fritzsch B. Auditory system development: primary auditory neurons and their targets. Annu Rev Neurosci 2002; 25: 51-101.

79. Webber A, Raz Y. Axon guidance cues in auditory development. Anat Rec A Discov Mol Cell Evol Biol 2006; 288: 390-396.

80. Coppola V, Kucera J, Palko ME, Martinez-De Velasco J, Lyons WE, Fritzsch B, Tessarollo L. Dissection of NT3 functions in vivo by gene replacement strategy. Development 2001; 128: 4315-4327. 
81. Farinas I, Jones KR, Tessarollo L, Vigers AJ, Huang E, Kirstein M, et al. Spatial shaping of cochlear innervation by temporally regulated neurotrophin expression. J Neurosci 2001; 21: 6170-6180.

82. Huang EJ, Liu W, Fritzsch B, Bianchi LM, Reichardt LF, Xiang M. Brn3a is a transcriptional regulator of soma size, target field innervation and axon path finding of inner ear sensory neurons. Development 2001; 128: 2421-2432.

83. Gu C, Rodriguez ER, Reimert DV, Shu T, Fritzsch B, Richards LJ, et al. Neurophilin-1 conveys semaphorin and VEGF signaling during neural and cardiovascular development. Dev Cell 2003; 5: 45-57.

84. Fritzsch B, Pauley S, Matei V, Katz DM, Xiang M, Tessarollo L. Mutant mice reveal the molecular and cellular basis for specific sensory connections to inner ear epithelia and primary nuclei of the brain. Hear Res 2005; 206: 52-63.

85. Greenwood D, Jagger DJ, Huang LC, Hoya N, Thorne $\mathrm{PR}$, Wildman SS, et al. P2X receptor signaling inhibits BDNF-mediated spiral ganglion neuron development in the neonatal rat cochlea. Development 2007; 134: 1407-1417. 